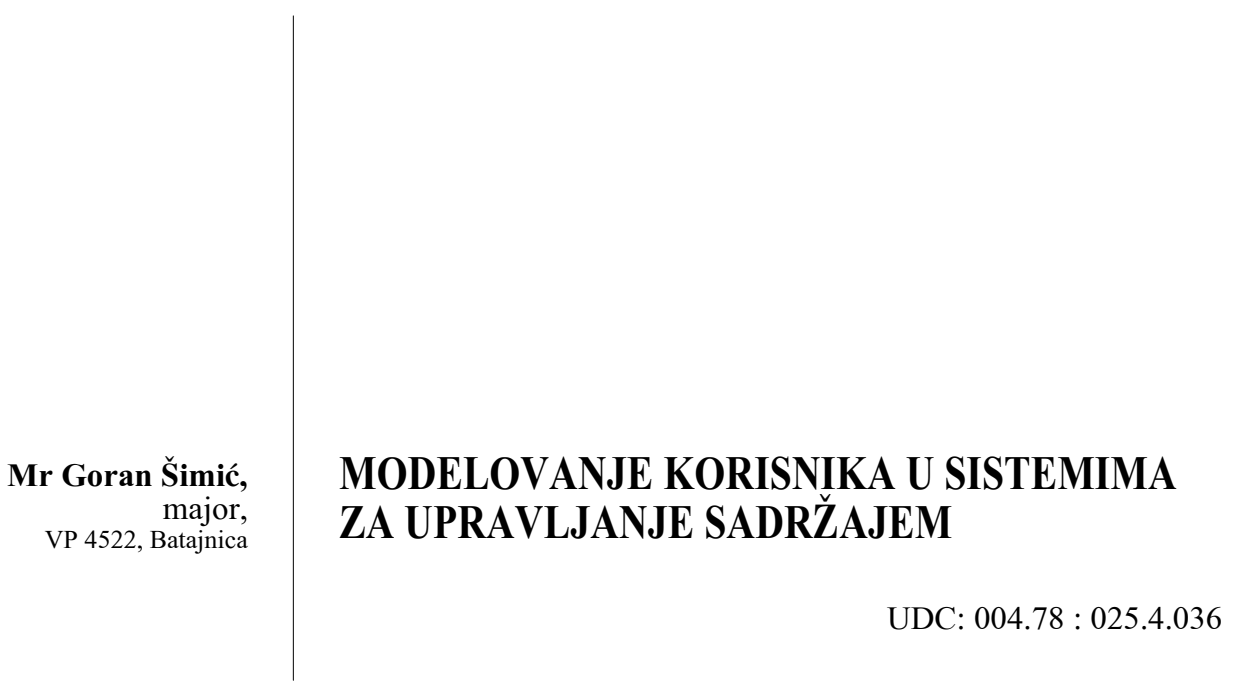

Rezime:

Sistemi za upravljanje informacionim sadržajima, zahvaljujući različitim funkcionalnim mogućnostima, vrlo su rasprostranjeni na Webu kao globalnoj mreži, $i$ u lokalnim mrežama institucija i organizacija različitih namena. Oni omogućavaju potpuno administriranje informacionim sadržajima $i$ njihovo dinamičko komponovanje i distribuciju. Iako postoje tehnološki preduslovi, ovi sistemi su fokusirani na sadržaje i nemaju podršku za njihovo personalizovano predstavljanje. Ovaj materijal opisuje mogućnosti proširivanja funkcionalnosti navedenih sistema radi adaptacije sadržaja koji se isporučuje korisnicima.

Ključne reči: modelovanje korisnika, sistemi za upravljanje informacionim sadržajem, Fazi logika, Web tehnologije, arhitekture, dizajn i aplikacija.

\title{
THE USER MODELING ISSUES IN THE CONTENT MANAGEMENT SYSTEMS
}

Summary:

Owing to different functional posibilities, there are many content management systems (CMS) on the Web and in the local networks of different organizations. They provide administering of different information content (delegation of content authoring and content using grants), as well as dinamical content composing and distribution. They are focused on their content. Although there are technology prerequisites, these systems lack content personalization. This paper describes the possibility of the CMS functional extending to adjust data structure and content with particular users' skills, interests and demands.

Key words: user modelling, content management systems, fuzzy logic, Web technologies, architectures, design, application.

\section{Uvod}

U savremenim informacionim sistemima, zahvaljujući objektno orijentisanom dizajnu i implementaciji, postavljeni su standardi koje softver mora da zadovolji, kako bi se iz faze razvoja mogao preneti u fazu korišćenja. Zbog toga aplikacije koje se nalaze u operativnoj upotrebi zadovoljavaju osnovne funkcionalnosti, specificirane projektnim zadacima.
Novi kvalitet, koji proizvođači nastoje da dostignu jeste adaptibilnost softvera prema mogućnostima, interesovanjima i potrebama korisnika. U tom smislu, model korisnika (user model - UM) predstavlja eksplicitnu reprezentaciju svojstava individualnog korisnika. Najveći broj aplikacija sadrži implicitni korisnički model. Sistemi koji obavljaju edukativne zadatke, kao što su inteligentni tutorski sistemi - ITS (Intelligent Tutoring Systems - 
ITS), ili sistemi sa adaptivnim hipermedijalnim sadržajima (Adaptive Hypermedia - AH) obično sadrže eksplicitni korisnički model (najčešće zvan studentski model). Ovaj model predstavlja jednu od najznačajnijih komponenti sistemske arhitekture. Navedeni sistemi su stručno (domenski) usko specijalizovani, tako da su njihovi korisnički modeli takođe specijalizovani i prilagođeni potrebama sistemskog zaključivanja (zaključivanja o korisniku).

S druge strane, postoji veliki broj domenski nezavisnih sistema kao što su sistemi za upravljanje učenjem (Learning Management System - LMS), sistemi za upravljanje sadržajem (Content Management Systems - CMS, objašnjeni u daljem tekstu) i sistemi za informacioni menadžment (Information Management Systems - IMS). Većina navedenih sistema nije fokusirana na edukaciju (izuzev LMS), niti na potrebe konkretnog korisnika. Njihovi administracioni (upravljanje sadržajem, dodela grupama i pojedincima prava pristupa i korišćenja Web servisa), autorizacioni (kreiranje i editovanje sadržaja) i kolaboracioni alati (saradnja grupa i pojedinaca bazirana na zajedničkim interesovanjima) boljeg su kvaliteta od alata $u$ inteligentnim $\mathrm{i}$ adaptivnim sistemima. Ista situacija je i u vezi struktuiranosti i standardizovanosti sadržaja. Domenski nezavisni sistemi su većinom fokusirani na sadržaj, zbog čega se šire koriste u edukaciji zasnovanoj na Web tehnologijama nego ITS i AH sistemi.

Danas postoji veliki broj sistema za upravljanje sadržajem (u daljem tekstu CMS). Oni su transparentni i dizajnerima obezbeđuju mogućnost nadgradnje funkcionalnosti, ali još uvek poseduju nedo- statak adaptibilnosti. Isti sadržaji isporučuju se različitim korisnicima na isti način. Ova ograničenja postoje iz dva razloga - jedan je slaba struktuiranost sadržaja (dekompozicija) a drugi je u vezi s modelovanjem korisnika. CMS ne sadrže korisnički model sa andragoškom i pedagoškom podrškom i sa mogućnošću rezonovanja. Postoje različite mogućnosti i prepreke u ugrađivanju korisničkog modela u postojeće CMS, kako bi se omogućila personalizacija sadržaja.

\section{Klasifikacija modela korisnika}

U sistemima kao što su ITS i AH korisnički model predstavlja eksplicitnu komponentu sistemske arhitekture. Nivo inteligencije (adaptibilnosti) navedenih sistema direktno je proporcionalan mogućnostima korisničkog modela da opiše sposobnosti, interesovanja i znanje realnog korisnika.

Sadržaj koji sistem dostavlja korisniku zasnovan je na karakteristikama modela. Ako model sadrži netačan ili nekompletan profil korisnika, akcije sistema će zakomplikovati korisnikove napore da se upozna, informiše ili nauči sadržaj.

$\mathrm{Ne}$ postoji univerzalan adaptibilan model korisnika, niti univerzalno prepoznatljiva ontologija za njegovo modelovanje. Nasuprot tome, postoje brojne različite klasifikacije korisničkih modela [1], koje se zasnivaju na načinu ažuriranja (statičko ili dinamičko), na osnovu sadržaja koje model podržava (specifični trenutni podaci ili opšti podaci dobijeni u procesu zaključivanja o korisniku) i na osnovu izvora informacija (upitnici i/ili testovi koje korisnik popunjava ili sistemsko rezonovanje o ponašanju na 
osnovu praćenja aktivnosti korisnika). Pojedini sistemi sadrže korisnički model koji nije namenjen postizanju adaptibilnosti. Takav model naziva se kanoničkim i u njemu su podaci o korisniku postojani onoliko koliko traje korisnička sesija sa sistemom.

Drugi način klasifikacije zasnovan je na znanju korisnika. Dva osnovna tipa su prekrivajući model i stereotipski model. Ova kategorizacija se učestalo koristi u sistemima za učenje [2]. Prekrivajući model je ograničen na ekspertsko znanje ugrađeno u sistem, i korisnika modeluje na osnovu razlike njegovog i sistemskog znanja iz konkretne naučne oblasti. Prekrivajući model je tipično implementiran u ITS (npr. ELM ART [3]) i AH sistemima (npr. KN-AHS [4]). Modelovanje pomoću stereotipova predstavlja svrstavanje korisnika u različite kategorije prema različitim kriterijumima (npr. u sistemu za preporučivanje na Amazon.com sajtu - prema interesovanjima ili u KNOME sistemu [5] - na osnovu nivoa znanja korisnika).

Postoje poteškoće u određivanju tipa stvarnih korisnika, jer ne postoje jasne granice između različitih tipova modela. Isti model može sadržati statičke i dinamičke podatke. Korisnički modeli mogu koristiti podatke direktno dobijene od korisnika, ali i podatke na osnovu zaključivanja o korisniku (implicitno, na osnovu podataka iz više korisničkih sesija).

\section{Ontologija modela korisnika}

Kod sistema koji su domenski nezavisni ne postoji generalno opredeljenje $u$ razvoju korisničkih modela. Ovi sistemi mogu imati različite namene (LMS - edukativnu, IMS - informativnu, CMS edukativnu i/ili informativnu). Zbog toga korisnički modeli domenski nezavisnih sistema moraju da podržavaju različite profile i različite podatke o korisniku. Ti podaci mogu se klasifikovati na različite načine. Autori obično specificiraju dve vrste podataka: o mentalnom stanju korisnika i o njihovim akcijama (tabela 1). Lični podaci o korisniku prikupljaju se eksplicitno (posredstvom upitnika i preliminarnih testova). Frekventnost i redosled korisničkih akcija (selektovanje materijala, vreme zadržavanja na pojedinačnim stranicama, navigacione putanje) predstavljaju implicitne izvore korisničkih podataka. Čest je slučaj da sistemi implicitno zaključuju o tome koju akciju, ili koji stereotip je najbolje primeniti na specificiranog korisnika.

Tabela 1

Struktura modela korisnika prema Kobsi, Kenemanu i Polu [6]

\begin{tabular}{|c|c|c|}
\hline \multicolumn{3}{|c|}{ Model korisnika } \\
\hline \multirow{2}{*}{ Podaci korisnika } & \multicolumn{2}{|c|}{ Podaci o korišćenju sadržaja } \\
\hline & Podaci iz posmatranja & Pravilnosti u korišćenju \\
\hline $\begin{array}{l}\text { Demografski podaci } \\
\text { Znanje } \\
\text { Veštine i sposobnosti } \\
\text { Iskustvo u korišćenju } \\
\text { sistema } \\
\text { Lične crte } \\
\text { Interesovanja i prioriteti } \\
\text { Ciljevi i planovi }\end{array}$ & $\begin{array}{l}\text { Izbor sadržaja } \\
\text { Ponašanje pri povre- } \\
\text { menom pregledanju } \\
\text { Brzina } \\
\text { Ostale afirmativne } \\
\text { akcije }\end{array}$ & $\begin{array}{l}\text { Učestanost korišćenja } \\
\text { Korelacija situacija } \\
\text { - akcija } \\
\text { Redosled akcija }\end{array}$ \\
\hline
\end{tabular}

Drugi primer ontologije modela korisnika predstavljen je preporukama $\mathrm{On}$ tologging konzorcijuma (slika 1) [2]. Ova ontologija sadrži više od dve grupe podataka, a to su: identifikacioni podaci (ime, adresa, datum rođenja, lični identifikacioni broj, pol i sl.), afilatorni podaci (zvanje, pripadnost timu, grupi, odeljenju, organizaciji i sl.), QCL (kvalifikacije, sertifikati i licence), podaci o radnom 


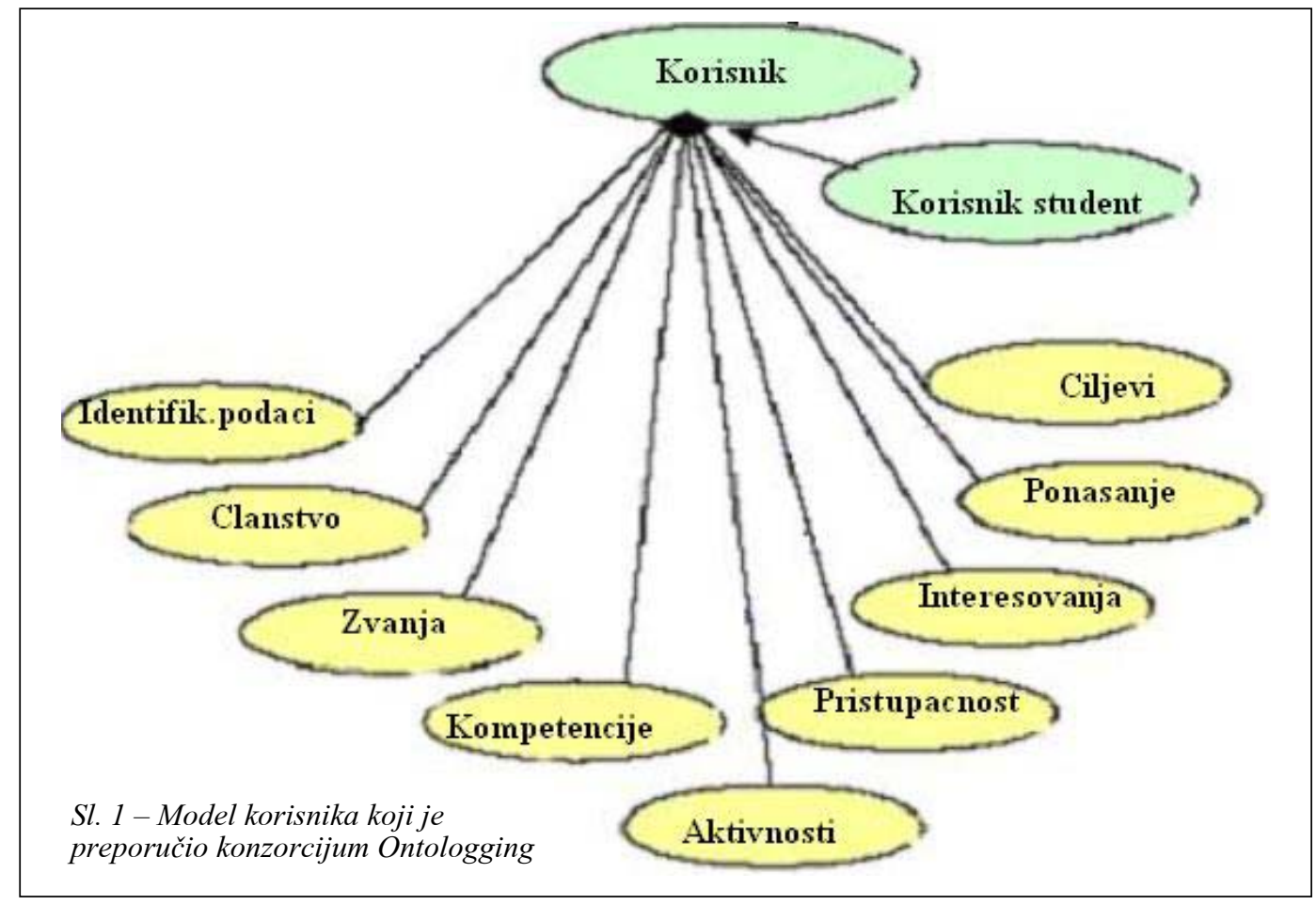

iskustvu, učestvovanje u aktivnostima, pristupačnost (jezici koje poznaje, stručne oblasti koje poznaje i područja od šireg interesovanja), hobiji, ponašanje (načini učestvovanja u različitim aktivnostima i spremnost da podeli znanje sa drugima) i ciljevi (lični ciljevi i aspiracije).

Kao u prethodnom primeru, model Ontologging sadrži podatke koji se eksplicitno dobijaju od korisnika (identifikacioni podaci, QCL, afilacija) i podatke koji se prikupljaju u toku korišćenja sistema i u procesu zaključivanja (aktivnosti, ponašanje, interesovanja). Eksplicitni podaci se, obično, predstavljaju korišćenjem literala (numerička i tekstualna reprezentacija), dok se implicitni podaci predstavljaju u vidu koncepata. Navedeni podaci mogu se razmatrati i prema postojanosti: perzistentni (statički) podaci (osnovni lični podaci) i tranzijentni (dinamički) podaci (prihvatanje preporuka, praćenje navigacije, stanje sesije, karakteristične greške) [7].

\section{Sistemi za upravljanje sadržajem}

Sistemi za upravljanje sadržajem predstavljaju Web aplikacije usmerene ka dva cilja: autorima obezbeđuju mesto na računarskoj mreži za smeštanje kreiranih sadržaja (lokalnoj ili globalnoj), a korisnicima omogućavaju pristup istim sadržajima radi ostvarivanja različitih zadataka (edukacija, informisanje, kupovina i sl.). Sadržaj može biti predstavljen u tekstualnom formatu ili u vidu različitih multimedijalnih sadržaja (fotografije, audio zapisi, video zapisi ili kompoziti). Nova generacija sistema za upravljanje 


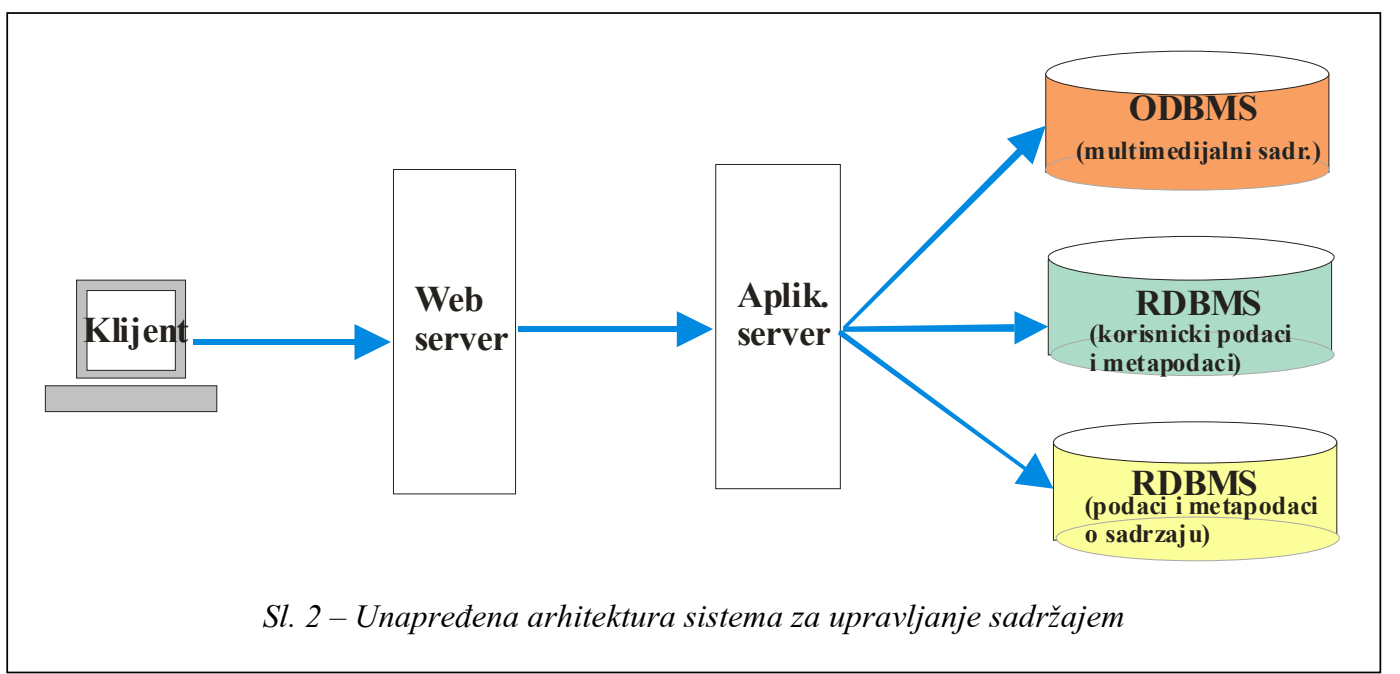

sadržajem omogućava komponovanje sadržaja u realnom vremenu, što je omogućeno specifičnom arhitekturom (slika 2).

Ovi sistemi razvijani su u različitim tehnologijama. Među njima su dve dominantne: sistemi zasnovani na Java tehnologijama i Microsoft .NET (DOT NET) komponente. Sistemi zasnovani na Javi obično su implementirani kao JSP (Java Servlet Pages - JSP) ili Servleti, sa Apache Web serverom kao distributorom sadržaja na prednjem kraju (npr. Apache Lenya [8], Ariadne LKP [9]). Kao alternativa postoje i sistemi za upravljanje sadržajem kao samostalni Web serveri u kojima je integrisana i aplikaciona logika (npr. OpenCMS [10]). S druge strane, .NET tehnologija integriše dobro poznate Microsoft Web proizvode u skalabilan model zasnovan na komponentama. Sistemi za upravljanje sadržajem mogu biti implementirani i u drugim tehnologijama: $P H P$ jezik kombinovan sa $M y S Q L$ sistemom za upravljanje bazama podataka (npr. Absolute Engine, phpWCMS i PHP Nuke), sistemi zasnovani na Payton jeziku i DTML-u (Document Template
Modelling Language - DTML), (npr. Plone server, Zope server sa objektnom bazom podataka).

Sistemi za upravljanje sadržajem mogu izvršavati različite administrativne zadatke, ali su isključivo fokusirani na sadržaj koji pohranjuju. Ponašanje aplikacione logike nije ograničeno, tako da postoje mogućnosti za implementaciju različitih Web servisa.

\section{Funkcija korisničkog modela u sistemima za upravljanje sadržajem}

Iako najveći broj sistema za upravljanje sadržajem ima mogućnost isporučivanja dinamički komponovanog sadržaja, to ne znači da je on (sadržaj) prilagođen individualnom korisniku. Da bi se omogućila personalizacija Web servisa, neophodno je da sistem sadrži model korisnika kao softversku komponentu. Korisnički model ima ugnježdenu strukturu u kojoj se prikupljaju podaci iz tekuće sesije, smeštaju podaci iz prethodnih sesija i čuvaju podaci dobijeni na osnovu zaključivanja sistema o korisniku. Siste- 
mi za upravljanje sadržajem smeštaju i manipulišu domenski različitim sadržajima. Različite (naučne) oblasti zahtevaju različite vrste podataka o korisniku i različite načine zaključivanja na osnovu stanja korisničkog modela. Na primer, potpuno se razlikuju zahtevi modelovanja $u$ domenu matematike $\mathrm{u}$ odnosu na domen muzičke umetnosti. Da bi korisnički model zaista bio koristan u sistemima za upravljanje sadržajem, potrebno je da podržava podatke za vrlo različite oblasti, što je teško izvodljivo.

Drugi problem modelovanja korisnika u razmatranim sistemima je akvizicija podataka. Ovi sistemi ne mogu u potpunosti predvideti sve moguće vrste (profile) korisnika. Korisnici sadržaja imaju različite ciljeve, motivaciju, interesovanja i sposobnosti. Zaključivanje o tome mora biti vrlo fleksibilno. Za razliku od prethodno pominjanih edukacionih sistema (sa adaptivnim hipermedijalnim sadržajima, inteligentni tutorski sistemi i sistemi za upravljanje učenjem), sistemi za upravljanje sadržajem ograničeni su na prikupljanje uglavnom implicitnih podataka $u$ toku korisničkih interakcija sa sistemom. Rezonovanje se, uglavnom, zasniva na: izboru sadržaja, praćenju navigacije, vremenu provedenom na svakoj pojedinačnoj stranici (sadržaj se isporučuje u vidu dinamički kreiranih HTML stranica) i akcijama koje dozvoljavaju isporučene stranice (korišćenje pomoći, slanje elektronske pošte, učestvovanje u diskusionim grupama, izbori iz lista, unos teksta, promena izgleda sadržaja i sl.).

Danas postoje mnogobrojni robustni i domenski uskospecijalizovani korisnički modeli. Za razmatrane sisteme su, nasuprot tome, potrebni generički modeli koji bi predstavljali agregaciju malog broja tzv. univerzalnih prenosivih modela koji su specijalizovani za različite zadatke. Činjenica da su sistemi za upravljanje sadržajem fokusirani na deklarativno (a ne proceduralno) znanje donekle ublažava probleme dizajna i implementacije korisničkog modela. Model mora omogućiti traganje za odgovarajućim profilom korisnika (model tracing, kao što je analitičko modelovanje studenta u LISP Tutor-u) i indukciju zasnovanu na pravilima i stablu odlučivanja (kao što je sintetičko modelovanje u Debuggy ili $A C M$ ).

Pored navedenih tipologizacija, postoji klasifikacija modela na osnovu definisanja korisničkog znanja. Prekrivajući model je domenski zavisan i zahteva precizno definisano ekspertsko (domensko) znanje. Ovaj tip modela pogodan je za domenski ograničene sisteme (AH sistemi, ITS, ili generalnije Knowledge Management System - KMS). Prekrivajući model, zbog specijalizovane namene, nije odgovarajući i za sisteme za upravljanje sadržajem. Model zasnovan na stereotipima omogućava kategorizaciju korisnika zasnovanu na različitosti domena (nauka, sport, muzika, itd.), što je u skladu sa činjenicom da razmatrani sistemi skladište multidomenske sadržaje.

\section{Moguće rešenje problema}

U sistemima za upravljanje sadržajem korisnički model treba da bude fokusiran na moguća unapređenja funkcionalnosti, kako bi se dobila adaptibilnost $u$ procesu komponovanja sadržaja koje je zahtevao korisnik (HTTP request). Moguće rešenje zasniva se na konceptu ra- 
slojenog korisničkog modela. Slično modelima korišćenim u sistemima za učenje, u kojima su socijalni koncepti predstavljeni na različitim nivoima - individualni, timski (grupni), klasni (generacijski), smer (specijalnost), u sistemima za upravljanje sadržajem može se izvršiti raslojavanje u smislu generalizacije specijalizacije. Na primer, identifikacioni podaci mogu se razmatrati na višem nivou opštosti (generalije), dok pristupačnost pripada mnogo specijalizovanijem nivou. Raslojen model omogućava profilisanje korisnika sa najmanjim skupom podataka. Počevši od prve korisničke sesije, sistem gradi korisnički model sloj po sloj - praktično izučava korisnika.

Slično modelu Ontologging konzorcijuma predloženo rešenje za razmatrane sisteme sadrži koncept generičkog korisnika (Generic User) u korenu stabla ontologije korisničkog modela (slika 3).

Ovaj koncept predstavlja podrazumevajući model koji se može izgraditi sa minimalnim setom podataka (identifikacioni podaci). Koncept domenskog stereotipa (DomainStereotype) jeste apstraktna komponenta modela koja enkapsulira potencijalno ponašanje korisnika na osnovu selekcije sadržaja. Trenutni model podržava tri domenski zasnovana korisnička stereotipa. Kulturni stereotip (Cultural) fokusiran je na umetnost, sport i slične sadržaje. Socijalni (Social) sadrži domene kao što su istorija, sociologija, psihologija, marketing, dok je stereotip zvan ExactScience usmeren na proceduralna znanja (matematika, fizika, programiranje i sl.). Sistemi za upravljanje sadržajem koriste stereotipove u konjukciji sa drugim konceptom - korisničkim profilom (User Profile). Profil, takođe, predstavlja apstraktnu komponentu. Sistem profiliše korisnika tokom sesija. $\mathrm{U}$ trenutnim implementacijama korisnik može biti u ulogama studenta - učenika (Learner), sakupljača informacija (Information Collector) ili se razmatra kao slučajni korisnik (OccasionalUser). Prvi profil je dizajniran za najnaprednije (najzainteresovanije) korisnike, a slučajni korisnik predstavlja drugu krajnost profilisanja. Kriterijumi za određivanje profila su vreme potrošeno na zahtevane sadržaje i navigacija tokom više sesija korisnika i sistema (slika 4).

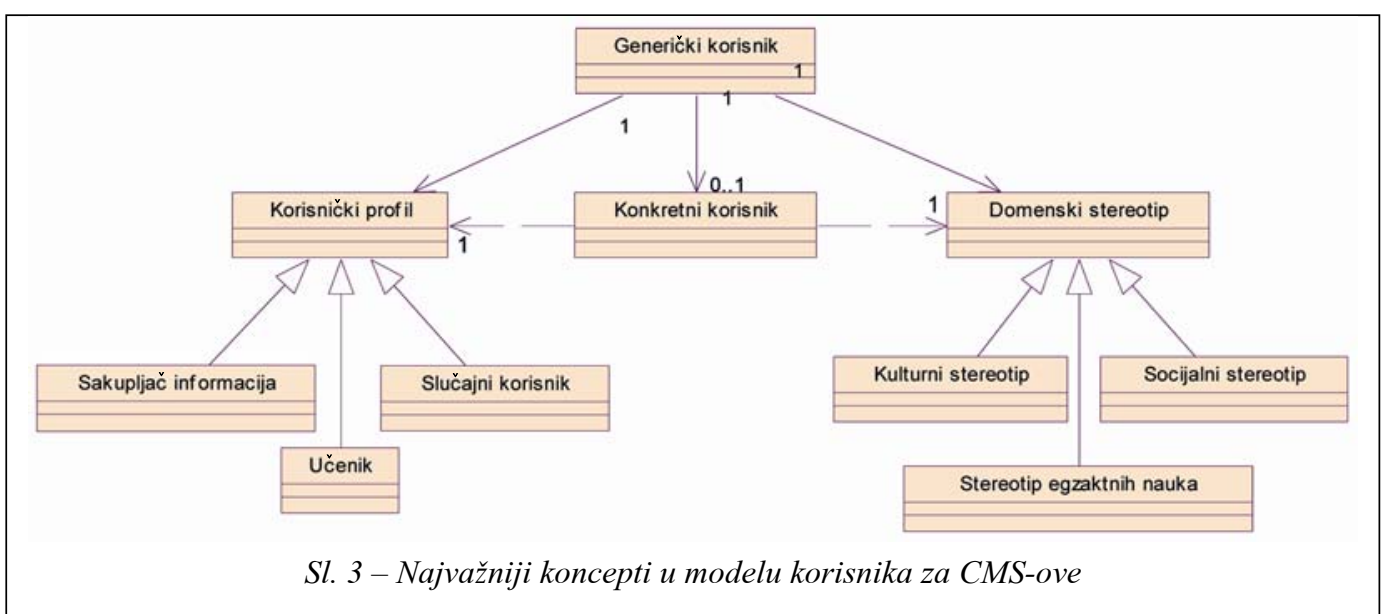




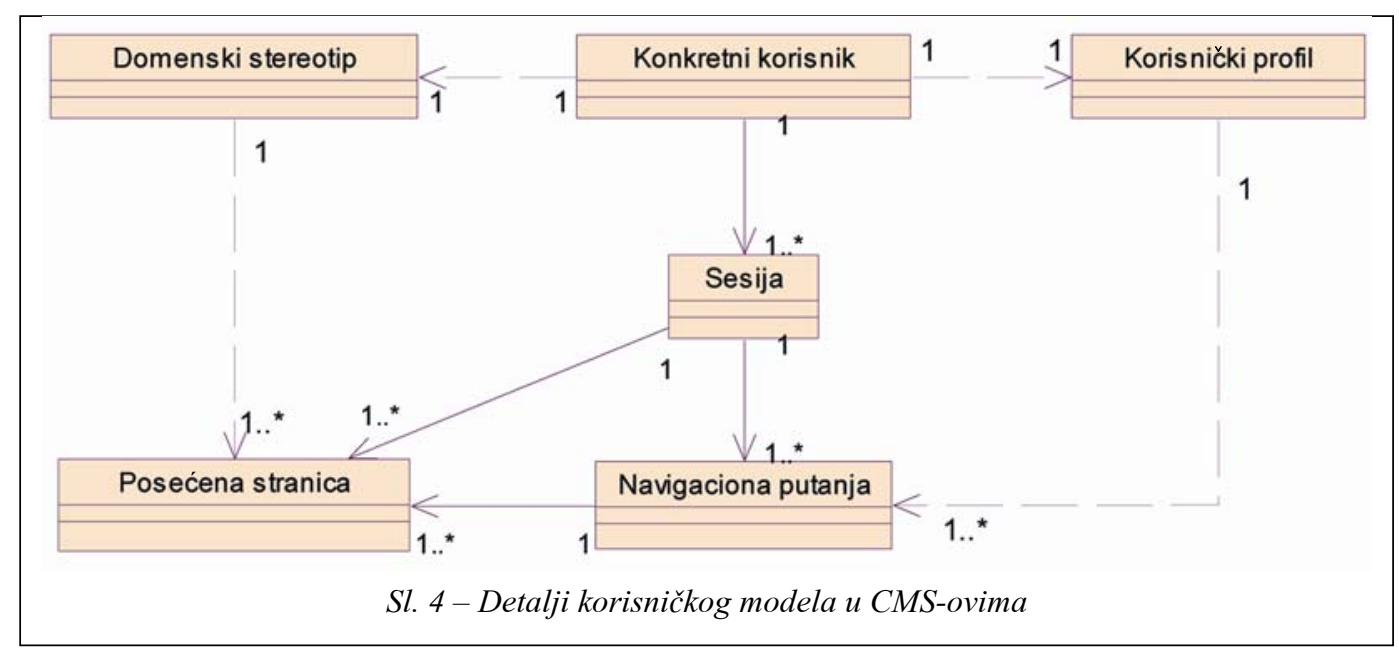

Dizajn konkretnog modela zahteva brojne dodatne koncepte (klase). U CMSovima glavni izvor podataka su korisničke sesije. Dodatne klase su kreirane upravo da smeste i ažuriraju podatke iz korisničkih sesija. Klasa sesije enkapsulira navigacionu putanju i informacije o posećenim sadržajima. Sistemski modul za zaključivanje koristi podatke sesije radi određivanja stereotipa i profila korisnika. Konkretni korisnik uvek se svrstava u jedan od prethodno opisanih (predefinisanih) profila i stereotipova. Konkretne klase izvedene iz klasa profila i stereotipova takođe mogu biti proširene novim konkretnim tipovima i podtipovima (klasama). Inteligencija sistema je predstavljena njegovom mogućnošću da prepozna novi stereotip - profil i ugradi ga u sistem.

\section{Rezonovanje}

U praksi nema jasnih granica između pojedinih profila i stereotipova. Isti korisnik se ne ponaša uvek isto u različitim sesijama. Često sistem ne može da prepozna nastojanja korisnika na osnovu njegovih akcija. Informacioni šum kom- plikuje zaključivanje o korisniku samo na osnovu pravila (Rule Based Reasoning - najpopularnija tehnika zaključivanja). Navigaciona statistika i merenje vremena može produkovati dvosmislene i iracionalne rezultate. Mogući način rešavanja ovog problema je korišćenje teorije Fazi skupova (Fuzzy set theory), koja dozvoljava rezonovanje uz prisustvo neodređenosti u podacima. Da bi se navedena teorija implementirala u konkretan sistem, potrebno je da se ontologija korisničkog modela proširi dodatnim Fazi konstrukcijama.

To bi značilo da su koncepti DomainStereotype i UserProfile predstavljeni odgovarajućim Fazi varijablama (tabela 2).

Tabela 2

Implementacija Fazi teorije u korisničkom modelu $C M S-a$

\begin{tabular}{|c|l|c|}
\hline Fazi varijable & \multicolumn{1}{|c|}{ Fazi termini } & Fazi skupovi \\
\hline \multirow{3}{*}{ Korisnički profil } & Slučajni korisnik & $(0,40)$ \\
\cline { 2 - 3 } & Sakupljač informacija & $(20,80)$ \\
\cline { 2 - 3 } & Učenik & $(60,100)$ \\
\hline
\end{tabular}

Svaka varijabla je opisana sopstvenim setom mogućih vrednosti (universe of discourse - UOD) i skupom Fazi ter- 


\begin{tabular}{|c|c|c|}
\hline Fuxzy lem & Santules & $\begin{array}{l}\text { Mernberstup } \\
\text { Degree }\end{array}$ \\
\hline \multirow[t]{4}{*}{ Occasional User } & 0 & 1 \\
\hline & 20 & 1 \\
\hline & 30 & 0,5 \\
\hline & 40 & 0 \\
\hline \multirow[t]{4}{*}{ Inlorenative Collectur } & 20 & 0 \\
\hline & 40 & 1 \\
\hline & 60 & I \\
\hline & 80 & 0 \\
\hline \multirow[t]{4}{*}{ Learner } & 60 & 0 \\
\hline & 70 & 0,5 \\
\hline & 80 & 1 \\
\hline & 100 & 1 \\
\hline
\end{tabular}

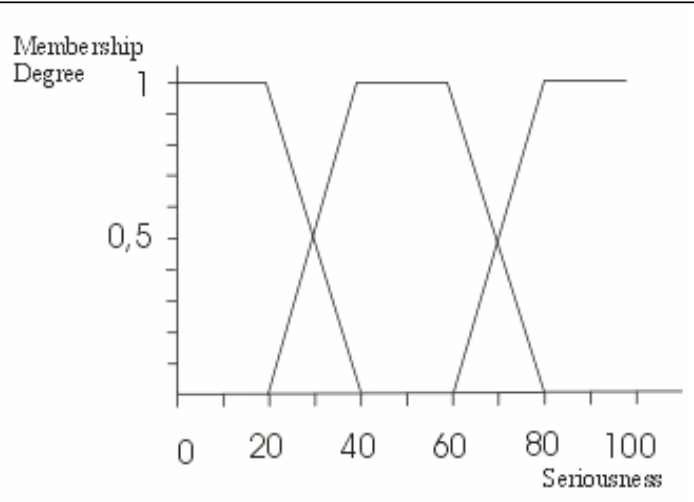

Sl. 5 - Stepen i funkcija pripadanja za Fazi termine o korisničkom profilu

mina. Konkretni korisnički stereotipovi i profili korišćeni su kao Fazi termini. Svaki pojedinačni Fazi termin je opisan posebnim Fazi skupom (slika 5). Fazi logika je u konkretnom primeru CMS-a korišćena radi merenja ozbiljnosti konkretnog korisnika sistema. Učenik (Learner) je najozbiljniji korisnik, dok slučajni korisnik (OccasionalUser) ima najmanje ozbiljne namere.

Uzorci predstavljeni u tabelama i na dijagramu odslikavaju raspodelu rezultata korisnika tokom sesije. Fazi skupovi (tabela 1) predstavljaju intervale odlučivanja dizajnirane za određivanje profila korisnika. Na taj način sistem može konstruisati distribuciju individualnih termina (primenjenih na pojedinačnu Fazi varijablu). Podaci prikupljani tokom više sesija mapirani su u stepene pripadanja Fazi terminima, kako bi se dobila njihova lingvistička reprezentacija. Kombinovanje Fazi termina sa logičkim operatorima omogućava lingvističko predstavljanje Fazi koncepata. Te konstrukcije mogu se koristiti kao premise (uslovi) Fazi pravila (slika 6). Ova pravila mogu se interpretirati u modulima za zaključivanje na bazi pravila (Rule engine).

Akcioni deo pravila generiše podatke koji se mogu tumačiti kao diskretne vrednosti koje se dalje mogu procesirati na konvencionalan način (tzv. proces defazifikacije). Iz predstavljenog opisa izuzet je koncept korišćenja modifikatora, koji dodatno poboljšavaju mogućnosti nelinearnog zaključivanja sistema sa Fazi logikom.

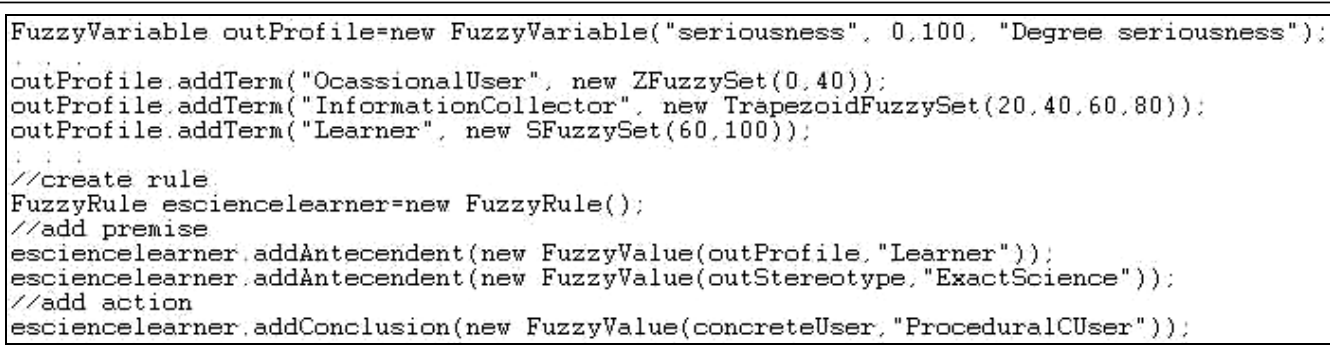

Sl. 6 - Prikaz konstrukcije Fazi pravila u alatu FuzzyJess 


\section{Zaključak}

Modelovanje korisnika u sistemima za upravljanje sadržajem razlikuje se od modelovanja učenika - studenata u edukativnim sistemima. U inteligentnim tutorskim, adaptivnim hipermedijalnim sistemima i sistemima za upravljanje znanjem, sadržaj je dizajniran isključivo za edukativne namene. Sadržaji u sistemima za upravljanje sadržajem nisu namenjeni samo učenju. Zbog toga je u njima znatno složenije modelovanje korisnika.

Složenija je i akvizicija podataka o korisniku. Pokušaji sa zadavanjem obimnih upitnika pri prvoj sesiji samo su odbijali korisnike da koriste sistem. Inicijalno testiranje, radi procene sposobnosti konkretnog korisnika, nemoguće je ako sistem ne poznaje namere korisnika (npr. da li želi da uči, ili samo da bude informisan). Zbog navedenih ograničenja, a da bi se korisnik uspešno modelovao u sistemima za upravljanje sadržajem, potrebno je prikupljanje mnogobrojnih implicitnih podataka (detalja) iz višestrukih sesija. Ti podaci dalje su korišćeni u procesu zaključivanja o konkretnom profilu i stereotipu korisnika. Prisustvo nepreciznih i dvosmislenih podataka nametnulo je potrebu korišćenja Fazi logike. Korišćeni koncepti za modelovanje korisnika sadrže vrednosti koje se preklapaju, a služe kao osnova za odlučivanje o profilu i stereotipu. Sistem mapira sakupljene podatke i određuje stepen pripadanja definisanih Fazi termina, dajući im lingvističku reprezentaciju koja se koristi u rezonovanju na osnovu pravila. Ovaj pro- ces je iterativan i inkrementalan, tako da se modelovanje korisnika nikada ne završava.

Drugi problem personalizacije sadržaja je njegovo predstavljanje. Različiti CMS-ovi struktuiraju sadržaj na različite načine. Neki od njih koriste ugnježdene SCORM editore (Sharable Content Object Reference Model - SCORM), koji ostavljaju autorima da sami opisuju svoje sadržaje. Mnogo veći broj sistema ne koristi standarde za eksplicitni opis sadržaja. Dobro dekomponovan sadržaj je pogodan za personalizaciju. Ako fragmenti nisu formalno opisani korišćenjem metapodataka, ili rečnika podataka, kao što su XSD (XML Schema), RDFS (Resource Definition Framework Schema), sistem neće moći da odredi pogodne sadržajne fragmente i da ih koristi u dinamičkom komponovanju.

Literatura:

[1] Ross, E.: Intelligent User Interfaces: Survey and Research Directions. University of Bristol. United Kingdom, (2000).

[2] Ontologging consortium: User modeling issues in the context of Knowledge Management Systems, resumed from http://www.ontologging.com/project/ (2004).

[3] ELM-ART (2003), http://www.psihologiue.uni-trier.de:8000/project/ELM/elmart.html

[4] Kobsa, A.; Mller, D. and Nill, A. KN-AHS: An Adaptive Hypertext Client of the User Modeling System BGP-MS. Proceedings of the Fourth International Conference on User Modeling, Hyannis, MA, pp. 99-105, 1994.

[5] Chin, D.: KNOME: Modeling What the User Knows in UC. In A. Kobsa and W. Wahlster (Eds.), User Models in Dialog Systems, Berlin: Springer-Verlag, (Symbolic Computation Series edited by D. W. Loveland), (1989) pp. 74-107.

[6] Kobsa, A.; Koenemann, J. and Pohl, W.: Personalized Hypermedia Presentation techniques for Improving Online Customer Relationships. The Knowledge Engineering Review 16(2), (2001) 111-155.

[7] Šimić, G.; Devedžić, V.: Building an intelligent system using modern Internet technologies, Expert Systems With Applications Journal, Elsevier, Vol. 25 (2003) 231-246.

[8] Apache Lenya http://cocoon.apache.org/lenya/

[9] ARIADNE: http://www.ariadne-eu.org/index.html

[10] Open CMS: http://www.opencms.org/opencms/opencms/ 